\title{
Resultados agronômicos e qualitativos da nova cultivar de trigo 'BRS Marcante'
}

\author{
Agronomic and qualitative results of the new wheat cultivar 'BRS Marcante'

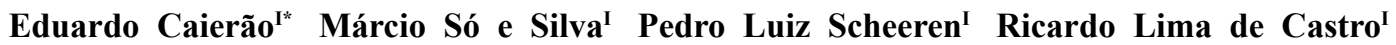 \\ Luiz Eichelberger ${ }^{I}$ Alfredo do Nascimento Junior ${ }^{I}$ Eliana Maria Guarienti ${ }^{I}$ \\ Martha Zavariz de Miranda ${ }^{I}$ João Leonardo Fernandes Pires ${ }^{\mathrm{I}}$ João Leodato Nunes Maciel ${ }^{\mathrm{I}}$ \\ Márcia Soares Chaves ${ }^{I}$ Flávio Martins Santana ${ }^{I}$ Leila Costamilan ${ }^{I}$ \\ Maria Imaculada Pontes Moreira Lima ${ }^{I}$ Douglas Lau Paulo Roberto Valle da Silva Pereira ${ }^{I}$ \\ José Pereira da Silva Júnior ${ }^{\mathrm{I}}$ Sirio Wiethölter ${ }^{\mathrm{I}}$ Gilberto Rocca da Cunha ${ }^{\mathrm{I}}$
}

\section{RESUMO}

A cultivar de trigo 'BRS Marcante' foi desenvolvida pela Embrapa, envolvendo um híbrido $F$, do cruzamento entre as linhagens PF 980533 e PF 970227 com a cultivar 'BRS Guamirim', realizado em telado, na Embrapa Trigo, no inverno de 2003. As gerações segregantes foram conduzidas pelo método genealógico e a linhagem resultante, nomeada de PF 080310. A cultivar caracteriza-se pela sua ampla capacidade de adaptação às condições de cultivo do sul do Brasil, pelo bom potencial de rendimento de grãos e qualidade industrial da classe Pão.

Palavras-chave: melhoramento, germoplasma, cereais, Triticum aestivum.

\section{ABSTRACT}

The wheat cultivar 'BRS Marcante' was developed by Embrapa, as a result a cross between $F$ hybrid between lines PF 980533 and PF 970227 with 'BRS Guamirim' and carried out in a green-house of Embrapa Wheat, on 2003 winter season. The segregate generations were conducted by genealogic method and the genotype resulted was named PF 080310. It has wide adaptation ability to south Brazilian conditions, high grain yield potential and belongs to Bread Class.

Key words: breeding, germplasm, cereals, Triticum aestivum.

A safra brasileira de trigo em 2013 foi de 5,5 milhões de toneladas de grãos (CONAB, 2014), frente a uma demanda anual de 10,5 milhões. Os estados do Rio Grande do Sul e Paraná, respectivamente, são os principais produtores do cereal e, juntos, representam, aproximadamente, $95 \%$ da produção nacional. Apesar desse déficit, que é suprido basicamente pela Argentina, o país exporta trigo, o que expõe a fragilidade na cadeia produtiva do cereal. Isso ocorre, entre outras razões, pela qualidade instável do grão colhido no Rio Grande do Sul, consequência de condições climáticas desfavoráveis e falta de estabilidade qualitativa das cultivares disponíveis aos produtores da região.

A Embrapa iniciou seu programa de melhoramento de trigo no Brasil em 1974 e, desde então, mais de uma centena de novas cultivares foram disponibilizadas ao produtor (SOUSA, 2004). Importância ímpar pode ser atribuída às cultivares 'Embrapa 16', 'BR 23', 'BRS 179' e 'BRS Guamirim'. O surgimento de vários programas de melhoramento no país durante as últimas décadas também contribuiu para a melhoria das características agronômicas e qualitativas das cultivares, o que se observa nas médias de rendimento de grãos obtidas na década de 70 em comparação com as atuais (aproximadamente $900 \mathrm{~kg} \mathrm{ha} \mathrm{h}^{-1} \mathrm{e}$ aproximadamente $2.500 \mathrm{~kg} \mathrm{ha}{ }^{-1}$, respectivamente) - CONAB, 2014. Somente no Rio Grande do Sul, por exemplo, foram recomendadas para cultivo, no ano de 2012, mais de 60 cultivares de diferentes obtentores (COMISSÃO, 2011). O programa de melhoramento de trigo da Embrapa tem como objetivo desenvolver cultivares de maior rendimento de grãos e com agrupamento de melhores características agronômicas, adequadas aos sistemas de produção atuais. Também é foco do programa a incorporação de resistências aos principais estresses bióticos e abióticos da cultura e priorização de trigos da classe Pão, estáveis, adequados à demanda prioritária do país.

'Embrapa Trigo, BR 285, km 294, 99001-970, Passo Fundo, RS, Brasil. E-mail: eduardo.caierao@embrapa.br.*Autor para correspondência. 
'BRS Marcante' é proveniente de cruzamento realizado no inverno de 2003, em telado da Embrapa Trigo, em Passo Fundo, RS, envolvendo um híbrido $\mathrm{F}_{1}$ do cruzamento entre as linhagens PF 980533 e PF 970227 com a cultivar 'BRS Guamirim'. A linhagem PF 980533 deriva de uma família de genótipos de excelente sanidade foliar, tanto para manchas foliares como ferrugem da folha. A linhagem PF 970227 tem como principal atributo a elevada força de glúten, fundamental na definição da classe comercial. 'BRS Guamirim' caracteriza-se pela ampla adaptação e excelente potencial de rendimento de grãos, tanto sob condições de baixo ou alto uso de insumos. No verão de 2004, foi conduzida a geração $F_{1}$ não simples, resultante do cruzamento, em telado, sendo colhida de forma massal, com seleção das melhores espigas. No mesmo ano, no inverno, as sementes compuseram o plantio segregante da geração $\mathrm{F}_{1: 2}$. Em 2005 e 2006, foram conduzidos os plantios "Plantas Segregantes Geração $\mathrm{F}_{2: 3}$ " e "Plantas Segregantes Geração $\mathrm{F}_{3: 4}$ ”, em parcelas de 3 linhas x $3 \mathrm{~m}$ de comprimento, selecionando-se, sempre, as plantas com destaque para sanidade foliar e boas características agronômicas (baixa estatura, colmo resistente e alta capacidade de afilhamento). Em 2007, as sementes das plantas selecionadas na geração anterior foram incluídas no plantio denominado de "Plantas Especiais - Geração $\mathrm{F}_{4: 5}$ ", de onde foi selecionada, como destaque, a planta $\mathrm{n}^{\circ} 5$, de melhor grão (bem formado, vermelho e sadio). As sementes resultantes dessa planta foram semeadas em densidade comercial (300 a 330 sementes aptas $/ \mathrm{m}^{2}$ ) no plantio denominado de "PO's ou Parcelas de Observação". Em 2008, a linhagem foi denominada de PF 080310 e avaliada no Ensaio Preliminar de Linhagens de Trigo da Embrapa, apresentando desempenho agronômico e qualitativo destacado, além do excelente potencial de rendimento de grãos. O histórico de seleção resumido da linhagem é F76789-0F-1F-5F-2F$5 \mathrm{~F}-0 \mathrm{~F}$, onde "0F" significa colheita massal e " $1 \mathrm{~F}$ ou $2 \mathrm{~F}$ ou $5 \mathrm{~F}$ " significa o número da planta colhida individualmente pelo método genealógico. Todas as gerações segregantes foram conduzidas na Embrapa Trigo, em Passo Fundo/RS. Nos anos de 2011 e 2012, a linhagem fez parte do ensaio para determinação do Valor de Cultivo e Uso, apresentando 5,5\% de superioridade em rendimento de grãos, quando comparada com a média das cultivares testemunhas 'BRS 327' e 'Quartzo' (Tabela 1). O percentual relativo em relação à média das testemunhas em 2011 e 2012 foi de $6,1 \%$ e $4,9 \%$, respectivamente.

A cultivar de trigo 'BRS Marcante' está enquadrada na Classe Pão, conforme IN no 38 do Ministério da Agricultura, Pecuária e Abastecimento (BRASIL, 2010). Seu perfil tecnológico está descrito na tabela 2. Das vinte e nove amostras consideradas para análise no laboratório de qualidade de grãos da Embrapa Trigo, quinze foram originadas da Região Tritícola de Adaptação 1 e quatorze originadas da Região Tritícola de Adaptação 2. A média de força de glúten e frequência de amostras na Classe Pão foi de $275 \times 10^{-4} \mathrm{~J}(80,0 \%)$ e $314 \times 10^{-4} \mathrm{~J}(71,4 \%)$, respectivamente, nas regiões 1 e 2 , sendo a média total de $294 \times 10^{-4} \mathrm{~J}(75,9 \%)$.

'BRS Marcante' é uma cultivar pertencente ao grupo bioclimático de primavera, de porte médio ( $78 \mathrm{~cm}$ na média das avaliações) e ciclo precoce (80 dias até o espigamento e 130 dias até a maturação). Caracteriza-se por ser moderadamente resistente ao crestamento, à debulha natural e à geada em fase vegetativa. Apresenta comportamento moderadamente suscetível à germinação da espiga em pré colheita e ao acamamento. Com relação às principais doenças da cultura, caracteriza-se por ser

Tabela 1 - Rendimento de grãos $\left(\mathrm{kg} \mathrm{ha}^{-1}\right)$ da cultivar de trigo 'BRS Marcante' e das testemunhas 'BRS 327' e 'Quartzo' e percentual relativo de desempenho na média de 22 locais de experimentação, conduzidos nos anos de 2011 e 2012. Passo Fundo: Embrapa Trigo, 2014.

\begin{tabular}{lccccc}
\hline Cultivar & 2011 & $\%$ & 2012 & $\%$ & Média \\
\hline 'BRS Marcante' & 5.104 & 106,1 & 4.894 & 104,9 & 4.999 \\
'BRS 327' & 4.908 & 102,1 & 4.629 & 99,2 & 4.769 \\
'Quartzo' & 4.709 & 97,9 & 4.701 & 100,8 & 4.705 \\
$\mathrm{~T}_{\mathrm{M}}$ & 4.809 & 100,0 & 4.665 & 100,0 & 4.737 \\
\hline
\end{tabular}

$\mathrm{T}_{\mathrm{M}}=$ média de rendimento de grãos das testemunhas 'BRS 327' e 'Quartzo'.

Locais de experimentação em 2011: Passo Fundo (2 épocas), São Borja (2 épocas), Três de Maio, Vacaria, Victor Graeff, Canoinhas, Chapecó, Guarapuava e Ponta Grossa.

Locais de experimentação em 2012: Passo Fundo (2 épocas), Cruz Alta, Santo Augusto, São Borja, São Luiz Gonzaga, Três de Maio, Vacaria, Chapecó, Guarapuava e Ponta Grossa. 
Tabela 2 - Perfil qualitativo da cultivar de trigo 'BRS Marcante' a partir das amostras da rede de experimentação conduzida pela Embrapa Trigo. Passo Fundo: Embrapa Trigo, 2014.

\begin{tabular}{lccc}
\hline Dados & Região 1 & Região 2 & $\begin{array}{c}\text { Média Região 1 } \\
\text { e 2 }\end{array}$ \\
\hline № de amostras & 15 & 14 & 29 \\
Força glúten (Média) $^{10}$ & 275 & 314 & 294 \\
Frequência $^{2}$ & $80 \%$ & $71,4 \%$ & $75,9 \%$ \\
Número de queda $^{3}$ & 388 & 349 & 366 \\
Índice de elasticidade $^{4}$ & 55,1 & 60,5 & 57,8 \\
Tenacidade (P) $^{5}$ & 112 & 119 & 116 \\
Extensibilidade (L) $^{6}$ & 73 & 72 & 72 \\
Relação P/L" & 1,6 & 1,8 & 1,7 \\
Minolta "L" 8 & 92,9 & 93,1 & 93.0 \\
Minolta "b" 9 & 8,5 & 8,5 & 8,5 \\
Classe indicativa & Pão & Pão & Pão \\
\hline
\end{tabular}

${ }^{1}$ Força de glúten, expressa em $10^{-4}$ Joules.

${ }^{2}$ Frequência de amostras dentro da Classe Pão.

${ }^{3}$ Número de queda, expresso em segundos.

${ }^{4}$ Índice de elasticidade, expresso em porcentagem.

5 Tenacidade ou pressão máxima de ruptura, expressa em milímetros.

${ }^{6}$ Extensibilidade ou média da abscissa na ruptura, expressa em milímetros.

${ }^{7}$ Relação entre tenacidade e extensibilidade.

${ }^{8} \mathrm{~L}^{*}=$ luminosidade. $\mathrm{L}^{*}=100$ (branco total); $\mathrm{L}^{*}=0$ (preto total). Cor L*, Minolta.

9 b* positivo $=$ tendência para a cor amarela; $b^{*}$ negativo $=$ tendência para a cor azul.

${ }^{10}$ Regiões Tritícolas de Adaptação no Brasil (BRASIL, 2008).

moderadamente resistente à giberela (Gibberella zeae) e moderadamente suscetível ao oídio (Blumeria graminis), ao vírus do mosaico do trigo (VMT) e à ferrugem da folha (Puccinia triticina).

A determinação dos descritores morfológicos da cultivar de trigo 'BRS Marcante' foi realizada nos ensaios de Distinguibilidade, Homogeneidade e Estabilidade (DHE), conduzidos pela Embrapa Trigo, em Passo Fundo (latitude de $28^{\circ} 15^{\prime} 46^{\prime \prime}$, longitude de 52 $24^{\prime} 24^{\prime \prime}$ e altitude de $687 \mathrm{~m}$ ), nos anos equivalentes em que participou do ensaio VCU. As características intrínsecas da cultivar estão descritas na tabela 3 .

A cultivar de trigo 'BRS Marcante' é indicada para cultivo nos estados do Rio Grande do Sul (regiões tritícolas de adaptação 1 e 2 BRASIL, 2008), Santa Catarina (regiões tritícolas de adaptação 1 e 2 - BRASIL, 2008) e sul do Paraná (região tritícola de adaptação 1 - BRASIL, 2008).
Tabela 3 - Principais descritores morfológicos da cultivar de trigo 'BRS Marcante' oriundos do ensaio para determinação da Distinguibilidade, Homogeneidade e Estabilidade (DHE), conduzido nos anos de 2011 e 2012. Passo Fundo: Embrapa Trigo, 2014.

\begin{tabular}{lll}
\hline Órgão $^{1}$ & \multicolumn{1}{c}{ Característica } & \multicolumn{1}{c}{ Descrição } \\
\hline Folha & $\begin{array}{l}\text { Posição da folha bandeira } \\
\text { Coloração das aurículas }\end{array}$ & $\begin{array}{l}\text { Intermediária/Ereta } \\
\text { Incolor }\end{array}$ \\
Colmo & $\begin{array}{l}\text { Espessura das paredes } \\
\text { Diâmetro }\end{array}$ & $\begin{array}{l}\text { Delgada a espessa } \\
\text { Médio }\end{array}$ \\
& Forma & Piramidal \\
Espiga & Coloração & Clara na maturação \\
& Arista & Aristada \\
& Comprimento do dente & Longo (> 7 mm) \\
Gluma & Forma do ombro & Reto \\
& & Alongado \\
& Forma & Vermelho \\
Grão & Coloração & Grão duro \\
& Textura & \\
\hline
\end{tabular}

${ }^{1}$ Órgão da planta em que foi realizada a avaliação.

A cultivar está registrada e protegida junto ao Ministério da Agricultura, Pesca e Agropecuária sob o número 30806, com certificado de proteção número 20140181, válido a partir de 20/05/2014..

\section{REFERÊNCIAS}

BRASIL. Ministério da Agricultura, Pecuária e Abastecimento. Instrução Normativa no 3 , de 14 de outubro de 2008. Diário Oficial [da] República Federativa do Brasil, Brasília, DF, 15 out. 2008. Seção 1, p.31.

BRASIL. Ministério da Agricultura, Pecuária e Abastecimento. Instrução Normativa no ${ }^{-38}$, de 30 de novembro de 2010. Diário Oficial [da] República Federativa do Brasil, Brasília, DF, 01 dez. 2010. Seção 1, p.2.

CONAB (COMPANHIA NACIONAL DE ABASTECIMENTO). Área, produção e rendimento de grãos de trigo no Brasil Safra 2013. Disponível em: $<\mathrm{http}: / /$ www.conab.gov.br $>$. Online. Acesso em: 27 maio 2014.

COMISSÃO BRASILEIRA DE PESQUISA DE TRIGO E TRITICALE. Informações técnicas para Trigo e Triticale Safra 2012. Dourados: Embrapa Agropecuária Oeste - Comissão Brasileira de Pesquisa de Trigo, 2011. 204p.

SOUSA, C.N.A. Cultivares de trigo indicadas para cultivo no Brasil e instituições criadoras. Passo Fundo: Embrapa Trigo, 2004. 138p. 